\title{
PENGARUH HIPNOSIS DALAM MENGURANGI NYERI SAAT PERAWATAN LUKA DI RS A. WAHAB SJAHRANIE SAMARINDA
}

\author{
Iwan Samsugito 1 \\ Program Studi D-III Keperawatan Fakultas \\ Kedokteran Universitas Mulawarman Samarinda
}

Email : 1556iwan@gmail.com

\begin{abstract}
ABSTRAK
Nyeri adalah suatu keadaan respon dari seseorang akibat adanya kerusakan jaringan yang mempengaruhi seseorang dan eksistensinya diketahui bila seseorang pernah mengalaminya. Rangsangan nyeri diterima oleh nosireseptor dan dihantarkan ke otak, pada saat perawatan luka terjadi gesekan atau rangsangan pada nosireseptor sehingga setiap perawat melakukan perawatan luka selalu terjadi nyeri dari intensitas ringan sampai berat. Hipnoterapi adalah suatu metode terapi menggunakan hipnosis, yang membuat pasien merasa rileks dan pikiran bawah sadarnya aktif sehingga mudah menerima sugesti dan mengabaikan respon yang lain.Tujuan penelitian ini untuk mengetahui pengaruh hipnosis dalam mengurangi nyeri saat perawatan luka di RS. A. Wahab Sjahranie Samarinda. Jenis penilitian yang digunakan dengan metode quasi eksperiment dengan rancangan penelitian satu kelompok prepost-test design without control (the one group pre-post test design). Dengan populasi 16 responden, teknik pengambilan sampel dengan consecutive sampling berdasarkan kreteria penelitian yang ditetapkan. Skala nyeri di ukur dengan dengan menggunakan Skala nyeri numerik rating scale (NRS). Analisa univariat menggunakan prosentase dan nilai ratarata dan bivariat menggunakan uji wilcoxon. Hasil analisa data didapatkan nyeri pasien dengan luka setelah operasi sebelum dihipnosis terbanyak adalah nyeri sedang 56,25 $\%$, sedangkan setelah dihipnosis mayoritas nyeri ringan sebanyak 93,75\%. berdasarkan hasil uji wilcoxon didapatkan hasil bahwa terdapat perbedaan skala nyeri pasien setelah operasi sebelum dan sesudah dihipnosis dengan nilai $p$ value $0,000<$ a 0,005 . Terdapat perbedaan yang bermakna nyeri pasien saat perawatan luka sebelum dan sesudah dihipnosis
\end{abstract}

Kata Kunci : hipnosis,nyeri, perawatan luka

\author{
*Corresponding Author : \\ Iwan Samsugito \\ Program Studi D-III Keperawatan \\ Fakultas Kedokteran Universitas Mulawarman \\ Email : 1556iwan@gmail.com
}


Jurnal Medika Karya IImiah Kesehatan

Vol 5, No.2. 2020

ISSN : 2654-945X (Online), 2541-4615 (Print)

Journal homepage : http://jurnal.itkeswhs.ac.id/index.php/medika

\section{PENDHULUAN}

Semua pasien setelah operasi mengalami nyeri pada daerah insisi pembedahan saat perawatan luka. Menurut Asosiasi Internasional untuk studi nyeri mendefinisikan nyeri adalah pengalaman sensorik dan emosional yang tidak menyenangkan terkait adanya kerusakan jaringan aktual atau pontensial(Bechert \& Abraham, 2009).

Penggantian balutan dilakukan untuk merawat luka agar terjadi penyembuhan namun sampai saat ini belum ada cara yang baik untuk dapat menghilangkan nyeri sehingga pasien sangat merasakan ketidaknyaman saat perawatan luka dan saat perawatan luka aspek nyeri sering di abaikan oleh perawat sehingga dapat mempengaruhi proses penyembuhan luka.

Tindakan keperawatan untuk mengatasi nyeri dapat dibedakan dalam dua kelompok utama, yaitu tindakan farmakologis dan tindakan nonfarmakologis. Tindakan farmakologis, misalnya: pemberian terapi obat-obatan. Sedangkan tindakan non farmakologis, misalnya: tindakan distraksi, teknik relaksasi, imajinasi terbimbing dan hipnosis(Tamsuri, 2007). Tindakan farmakologis dapat mengurangi nyeri pada saat pasien tidak dilakukan perawatan luka namun saat perawatan luka terjadi sentuhan antara bahan atau alat perawatan luka dengan permukaan luka sehingga pasti terjadi nyeri.

Pikiran sadar dan bawah sadar dibatasi oleh critical factor, untuk dapat menembus critical factor dapat dilakukan diantaranya adalah perkataan orang yang memiliki otoritas dan hipnosis(Setiawan, 2010; Wong \& Hakim, 2010). Perawat memiliki otoritas terhadap pasien sehingga mempermudan dalam penerapan hipnosis. Hipnosis membuat pasien mengalami rileksasi fisik dan pikiran. pikiran bawah sadar yang aktif mengambil alih pikiran sadar. saat pikiran bawah sadar pasien aktif perawat dapat diberikan sugesti untuk mengabaikan perasan nyeri yang terjadi saat perawatan luka sehingga hipnosis dapat diterapkan untuk membantu pasien mengabaikan nyeri. Saat perawat mengganti balutan pasien merasakan nyaman, senang dan perawat dapat melakukan perawatan luka dengan baik sehingga luka dapat cepat sembuh. Oleh karenanya penelitian ini diharapkan dapat meningkatkan rasa nyaman pasien karena terbebas dari rasa nyeri pada saat perawatan luka dan luka menjadi cepat sembuh.

Hipnoterapi terhadap luka telah diteliti sebelumnya, antara lain hipnoterapi dapat mengurangi nyeri saat pemasangan infus pada pasien anak (Liossi, White, \& Hatira, 2009), dapat menurunkan nyeri pada pasien nyeri kronik (Nugraha \& Adisaputro, 2017). Selain itu hipnosis diri sendiri dapat mengurangi penggunaan obat anti nyeri yang setara dengan morfhin (Manworren et al., 2018) . Rasa nyeri pasien akibat luka operasi ortopedi juga dapat diturunkan melalui hipnoterapi (Subiyanto, Sitorus, \& Sabri, 2008). Namun pada penelitian ini kami melakukan hipnosis pada

*Corresponding Author :

Iwan Samsugito

Program Studi D-III Keperawatan

Fakultas Kedokteran Universitas Mulawarman

Email : 1556iwan@gmail.com 
Jurnal Medika Karya IImiah Kesehatan

Vol 5, No.2. 2020

ISSN : 2654-945X (Online), 2541-4615 (Print)

Journal homepage : http://jurnal.itkeswhs.ac.id/index.php/medika

responden saat perawatan luka (mengganti balutan)

\section{METODE PENELITIAN}

Penelitian ini dilakukan dengan metode quasi eksperiment dengan rancangan penelitian satu kelompok prepost-test design (the one group pre-post test design). Metode ini dilakukan dengan memberi perlakukan pada objek penelitian tanpa adanya kelompok kontrol (Dharma, 2011). Penelitian dilakukan di Rumah Sakit A. Wahab Sjahranie Samarinda pada bulanSeptember dan Oktober 2019. Sebelum dilakukan ganti balutan responden diukur sekala nyerinya kemudian dilakukan hipnosis saat akan diganti balutan. Saat pengantian balutan responden dalam keadaan terhipnosis dan pengukuran sekala nyerinya setelah selesai ganti balutan. Jumlah responden sebanyak 16 orang dengan teknik pengambilan sampel consecutive sampling. Skala nyeri di ukur dengan dengan menggunakan Skala nyeri numerik rating scale (NRS) yang memiliki keandalan yang baik dengan nilai 0 tidak nyeri. 1-3 nyeri ringan, 4-6 nyeri sedang dan 7-10 nyeri berat (Brevik et al., 2008; Castarlenas, Jensen, Von Baeyer, \& Miró, 2017)

Adapun kreteria inklusi dan eksklusi sampel sebagai berikut Kreteria inklusi :

1. usia lebih dari 18 tahun

2. luka akibat operasi dengan skala nyeri $4 \mathrm{~s} / \mathrm{d} 10$

3. Bersedia menjadi responden
4. Kooperatif.

Kreteria eksklusi :

1. Mengalami depresi

2. Luka bakar

Analisa data dengan menggunakan uji statistik paired t-test karena data tidak berdistribusi normal maka di pakai uji Wilcoxon(Dahlan, 2008)

\section{HASIL DAN PEMBAHASAN}

Analisa univariat dalam penelitian ini menjabarkan Karakteristik Responden Berdasarkan Usia, Jenis Kelamin, Pendidikan, Pekerjaan Dan Pengalaman Dirawat serta distribusi frekwensi skala nyeri sebelum dan sesudah di hipnosis saat mengganti balutan luka operasi Di RS A. Wahab Sjahranie 2019

Tabel 1.Distribusi Frekwensi Karakteristik Responden Berdasarkan Usia, Jenis Kelamin, Pendidikan, Pekerjaan Dan Pengalaman Dirawat Di RS A. Wahab Sjahranie 2019

\begin{tabular}{|c|c|c|c|}
\hline \multicolumn{4}{|c|}{$\begin{array}{l}\text { Karakteristik } \\
\text { Usia }\end{array}$} \\
\hline Usia & $17-25$ & 3 & 9,4 \\
\hline & $26-35$ & 4 & 12,5 \\
\hline & $36-45$ & 6 & 18,8 \\
\hline & $46-55$ & 13 & 40,6 \\
\hline & $56-65$ & 6 & 18,8 \\
\hline \multicolumn{4}{|c|}{ Jenis kelamin } \\
\hline & Pria & 14 & 43,8 \\
\hline & Wanita & 18 & 56,3 \\
\hline \multicolumn{4}{|c|}{ Pendidikan } \\
\hline & SD & 7 & 21,9 \\
\hline & SLTP & 5 & 15,6 \\
\hline & $\begin{array}{l}\text { SLTA } \\
\text { PT }\end{array}$ & $\begin{array}{c}13 \\
7\end{array}$ & $\begin{array}{l}40,6 \\
21,9\end{array}$ \\
\hline
\end{tabular}

Pekerjaan

Tidak berkerja

\section{*Corresponding Author :}


Jurnal Medika Karya IImiah Kesehatan

Vol 5, No.2. 2020

ISSN : 2654-945X (Online), 2541-4615 (Print)

Journal homepage : http://jurnal.itkeswhs.ac.id/index.php/medika

$\begin{array}{lcc}\text { PNS/TNI/POLRI } & 1 & 3,1 \\ \text { Swasta } & 21 & 65,6 \\ \text { Pelajar/Mahasiswa } & 1 & 3,1 \\ \text { Pengalaman di rawat } & & \\ \text { 1 kali } & 14 & 43,8 \\ \text { 2 kali } & 10 & 31,3 \\ \text { 3 kali } & 7 & 21,9 \\ \text { >3 kali } & 1 & 3,1\end{array}$

Dari 16 responden terbanyak usia 46-55 tahun 13 responden $(40,6 \%)$, jenis kelamin terbanyak wanita 18 responden $(56,3 \%)$,

pedidikan terbanyak SLTA 13 responden (40,6\%), pekerjaan terbanyak Swasta 21 Responden (65,6 \%) dan penagalaman di rawat 1 kali sebanyak 14 responden $(43,8 \%)$

Tabel 2 distribusi frekwensi skala nyeri sebelum dan sesudah di hipnosis saat mengganti balutan

\begin{tabular}{lcc}
\hline Skala Nyeri & Frekwensi & Persentase \\
\hline Sebelum di & & \\
Hipnosis & & \\
Ringan (1-3) & 0 & 0 \\
Sedang (4-6) & 9 & 56,25 \\
Berat (7-10) & 7 & 43,75 \\
& & \\
Setelah di & & \\
Hipnosis & & \\
Ringan (1-3) & 15 & 93,75 \\
Sedang (4-6) & 1 & 6,25 \\
Berat (7-10) & 0 & 0
\end{tabular}

Berdasarkan tabel 2 di atas pasien sebelum dihipnosis paling banyak mengalami neyri sedang sebanyak $56,25 \%$ sedangkan setelah dihipnosis paling banyak nyeri ringan sebanyak $93,75 \%$

Tabel 3. Nilai Rata Rata Tingkat Nyeri Sebelum dan sesudah di hipnosis Saat Ganti Balutan Di
$3,1 \quad$ RS A. Wahab Sjahranie Samarinda

Nilai rata rata Nilai rata rata

skala nyeri skala nyeri

Sebelum ganti Saat ganti

balutan balutan

dilakukan

hipnosis

Skala Kualitas Skala Kualitas

\section{6,3 Sedang 1,7 Ringan}

Berdasarkan tabel 3 di atas nilai rata-rata skala nyeri sebelum di hipnotis 6,3 sedangkan setelah di hipnotis 1,7

Tabel 4. Uji $t$ berpasangan nyeri sebelum dan sesudah Di Hipnosis Saat Mengganti Balutan di RS AW. Sjahranie Samarinda

\begin{tabular}{|c|c|c|c|c|c|}
\hline Nyeri & $\mathrm{N}$ & Mean & SD & SE & $\mathrm{p}$ Value \\
\hline $\begin{array}{l}\text { Sebelu } \\
\text { m } \\
\text { Hipnos } \\
\text { is }\end{array}$ & 16 & 6,313 & 1,302 & 0,325 & \\
\hline $\begin{array}{l}\text { Sesud } \\
\text { ah } \\
\text { Hipnos } \\
\text { is }\end{array}$ & 16 & 1,688 & 0,793 & 0,198 & $0,000^{*}$ \\
\hline
\end{tabular}

Berdasarkan tabel 4 di atas dapat dilihat hasil uji t diperoleh $P$ value 0,000 berarti kurang dari 0,05 maka Ho ditolak artinya hipnosis berpengaruh terhadap penurunan intensitas nyeri pada saat perawatan luka

\section{PEMBAHASAN}

Dari hasil penelitian di atas diperoleh nilai rata-rata intensitas nyeri sebelum dihipnosis 6,3 dan setelah di hipnosis turun menjadi 1,6 serta nilai $P$ value sebesar 0,000 berarti kurang dari nilai $\alpha$ 0,005 maka dapat dinyatakan bahwa ada pengaruh yang signifikan hipnosis dalam penurunan nyeri saat perawatan

\section{*Corresponding Author :}


Jurnal Medika Karya IImiah Kesehatan

Vol 5, No.2. 2020

ISSN : 2654-945X (Online), 2541-4615 (Print)

Journal homepage : http://jurnal.itkeswhs.ac.id/index.php/medika

luka, hal ini sejalan dengan penelitian (Subiyanto et al., 2008) dengan judul terapi hipnosis terhadap penurunan sensasi nyeri pasca bedah ortopedi serta penelitian (Ngatwadi, Mutdasir, \& Mulyadi, 2018) dengan judul Perbedaan efektifitas pengaruh hipnoterapi dan teknik relaksasi nafas dalam terhadap nyeri sendi pada penderita arthritis rheumatoid kedua penelitian ini menghasilkan bahwa hipnosis dapat mengurangi intensitas nyeri.

Hipnosis dapat mengurangi intensitas nyeri karena kerja dari pikiran bawah sadar. Secara umum pikiran manuasi terdiri dari pikiran sadar dan bawah sadar dan diantara pikiransadar dan bawah sadar terdapat pembatas yang disebut Critical factor. Pikiran bawah sadar tempat manusia menyimpan memori, keyakinan, nilai-nilai, emosi, kepribadian dan ingatan jangka panjang (Hunter, 2011). berespon sesuai kondisi. Misalnya klien Semua yang tersimpan dalam pikiran bawah sadar dianggap benar oleh pemiliknya sehingga jika ada stimulus yang sama atau mirip sesuai memori yang disimpan maka pikiran bawah sadar akan memerintahkan pikiran sadar untuk menyimpan memori nyeri yang pernah dialami pada masa lalu saat setelah operasi dan mengalami nyeri maka respon yang diberikan oleh bawah sadar akan sama dengan nyeri masa lalu. Hipnosis adalah suatu metode yang alamiah membuat sesorang rileks dan mudah menerima sugesti (Gani, Setio, \& Amarta, 2012)

kondisi terhipnosis terjadi penurunan fungsi analisis logis pikiran sadar sehingga memungkinkan individu masuk ke dalam kondisi bawah sadar(Fachri, 2008) sehingga pikiran sadar tidak aktif dan pikiran bawah sadar sangat aktif(Gunawan, 2009) dengan aktifnya pikiran bawah sadar maka individu menjadi fokus dengan sugesti yang di berikan oleh terapis untuk tidak merasakan nyeri saat perawatan luka dilakukan. Libeault mengatakan hipnosis dimunculkan dengan menggunakan sugesti, sugesti nyeri tidak dirasakan karena pikiran klien megabaikan perasaan nyeri yang terjadi karena klien fokus pada sugesti yang diberikan (Fachri, 2008) saat terhipnosis klien mengalami relaksasi yang dalam dan memberikan rasa nyaman, kondisi rileks ini menyebabkan otak mengeluarkan hormon endorphin yang dapat mengurangi sensasi nyeri (Haruyama, 2013)

Sugesti yang diberikan pada penelitian ini adalah membuat klien mengalami relaksasi dan tidak merasakan nyeri pada luka operasi setelah perawat memberikan cairan $\mathrm{NaCl}$ atau disinfektan pada balutan luka atau luka. Terjadinya penurunan tingkat nyeri pada klien yang dirawat lukanya memberikan dampak positif pada klien yaitu 1. Klien merasa nyaman selama perawatan luka karena terbebas dari nyeri. 2. Luka pasien dapat cepat sembuh karena perawat dapat melakukan perawatan luka dengan maksimal sesuai prosedur. 
Jurnal Medika Karya IImiah Kesehatan

Vol 5, No.2. 2020

ISSN : 2654-945X (Online), 2541-4615 (Print)

Journal homepage : http://jurnal.itkeswhs.ac.id/index.php/medika

\section{SIMPULAN}

Hipnosis dapat menurunkan tingkat nyeri pada klien yang dilakukan perawatan luka. Dengan berkurangnya tingkat nyeri pada klien yang di rawat lukanya membuat klien merasa nyaman dan lukanya cepat sembuh karena perawat dapat maksimal melakukan perawatan luka saat perawatan luka dan dapat digunakan sebagai bagian praktek keperawatan profesional sehinga perawat perlu mendapatkan pelatihan tentang hipnosis (medikal hipnosis).

\section{SARAN}

Dengan adanya hasil penelitian ini diharapkan perawat dapat mempelajari hipnosis terutama fokus pada medical hypnosis sehingga saat melakukan perawatan luka pasien merasa nyaman, tidak mengeluh nyeri saat merawat luka, bisa melakukan perawatan luka dengan baik sehingga luka cepat sembuh

\section{DAFTAR PUSTAKA}

Bechert, K., \& Abraham, S. E. (2009). Pain Management and Wound Care. Journal of the American College of Certified Wound Specialists, 1(2), 65-71. https://doi.org/10.1016 /j.jcws.2008.12.001

Brevik, H., Borchgrevink, P. ., Allen, S. ., Rosselend, L. ., Romundstad, L., HalsBrevik, F. ., ... Stubhaug, A. (2008). *Corresponding Author :

Assessment of pain.
British Journal of Anaesthesia, 101(1), 17-24. https://doi.org/10.1017/CBO 9780511544835.004

Castarlenas, E., Jensen, M. P., Von Baeyer, C. L., \& Miró, J. (2017). Psychometric properties of the numerical rating scale to assess selfreported pain intensity in children and adolescents. Clinical Journal of Pain, 33(4), 376-383. https://doi.org/10.1097/AJP. 0000000000000406

Chester, S. J., Tyack, Z., De Young, A., Kipping, B., Griffin, B., Stockton, K., ... Kimble, R. M. (2018). Efficacy of hypnosis on pain, woundhealing, anxiety, and stress in children with acute burn injuries: a randomized controlled trial. Pain, 159(9), 1790-1801. https://doi.org/10.1097/j.pai n.0000000000001276

Dahlan, M. S. (2008). Statistik untuk Kedokteran dan Kesehatan. Jakarta: Salemba Merdeka.

Dharma, K. K. (2011). Metodologi Penelitian Keperawatan. Jakarta: Trans Info Media.

Fachri, A. H. (2008). The Real Art Of Hypnosis (1st ed.; Er. Hidayat, Zein.; Normalita, ed.). Jakarta: GagasMedia.

Gani, A. H., Setio, L., \& Amarta. (2012). Dental Hipnosis. Yogyakarta: Pohon Cahaya.

Gunawan, A. (2009). Hypnotherapy The Art Of Subconscious Restructuring (3rd ed.). Jakarta: Gramedia. 
Haruyama, S. (2013). The Miracle Of Endorphin (1st ed.). Jakarta: Mizan Pustaka.

Hunter, R. A. (2011). Seni Hipnoterapi (4th ed.). Jakarta: indeks.

Liossi, C., White, P., \& Hatira, P. (2009). A randomized clinical trial of a brief hypnosis intervention to control venepuncturerelated pain of paediatric cancer patients. Pain, 142(3), 255-263. https://doi.org/10.1016/j. pain.2009.01.017

Manworren, R. C. B., Anderson, M. N., Girard, E. D., Ruscher, K. A., Verissimo, A. M., Palac, H., .. Hight, D. (2018). Postoperative Pain Outcomes after Nuss Procedures: Comparison of Epidural Analgesia, Continuous Infusion of Local Anesthetic, and Preoperative SelfHypnosis Training. Journal of Laparoendoscopic and Advanced Surgical Techniques, 28(10), 1234-1242.

https://doi.org/10.1089/la p.2017.0699

Ngatwadi, Mutdasir, \& Mulyadi. $\begin{array}{lr}\text { (2018). } & \text { Perbedaan } \\ \text { Efektifitas Pengaruh } \\ \text { Hypnotherapy Dan } \\ \text { Teknik Relaksasi } \\ \text { Nafas r Dalam } \\ \text { Terhadap } & \text { Nyeri Sendi } \\ \text { Padar Penderita } & \text { Prthritis Rheumatoid. }\end{array}$

*Corresponding Author:

Iwan Samsugito

Program Studi D-III Keperawatan

Fakultas Kedokteran Universitas Mulawarman

Email : 1556iwan@gmail.com
Jurnal IImu Keperawatan, 6(1), 15-30.

Nugraha, L. N., \& Adisaputro, S. (2017). Hipnoterapi Pada Pasien Nyeri Kronik. Berkala Ilmiah Kedokteran Duta Wacana, 2(2), 317. https://doi.org/10.21460/bik dw.v2i2.54

Setiawan, A. (2010). Komunikasi Dahsyat Dengan Hipnosis. Jakarta: Visimedia.

Subiyanto, P., Sitorus, R., \& Sabri, L. (2008). Terapi Hipnosis Terhadap Penurunan Sensasi Nyeri Pascabedah Ortopedi. Jurnal Keperawatan Indonesia, 12(1), 47-52. https://doi.org/10.7454/jki.v1 2i1.199

Tamsuri, A. (2007). Konsep Dan Penangan Nyeri. Jakarta: EGC.

Wong, W., \& Hakim, A. (2010). Dahsyatnya Hipnosis (6th ed.). Jakarta: Visimedia. 
Jurnal Medika Karya IImiah Kesehatan

Vol 5, No.2. 2020

ISSN : 2654-945X (Online), 2541-4615 (Print)

Journal homepage : http://jurnal.itkeswhs.ac.id/index.php/medika 